\title{
AVALIAÇÃO DA APRENDIZAGEM EM EDUCAÇÃO ONLINE
}

\author{
Dilmeire Sant'Anna Ramos Vosgerau ${ }^{* *}$
}

$E$

m 2003, com a publicação do livro Educação online, o professor Marco Silva conseguiu, com muita pertinência, recolher e organizar artigos que contribuíram para o esclarecimento de diversas questôes que estavam sendo levantadas naquela época, relativas ao planejamento e implantação de sistemas educacionais na modalidade a distância. Contribuindo diretamente para o esclarecimento das teorias que fundamentavam as práticas pedagógicas que começavam a ser delineadas na educação a distância no Brasil, como também colaborando com os pesquisadores na compreensão da legislação vigente sobre esta modalidade de ensino, tanto no meio acadêmico quanto no corporativo.

Passados três anos da publicação desta iniciativa, observamos, no panorama nacional, diversos modelos acadêmicos e corporativos de educação online sendo realizados, passando de um período no qual questionávamos "como fazer" para outro, em que questionamos "se estamos fazendo adequadamente".

$\mathrm{O}$ uso intensificado desta modalidade de ensino tem levado diferentes profissionais que atuam nesta área, como planejadores, desenhistas instrucionais, professores, tutores e pesquisadores, a formular outras questôes ainda mais específicas, tais como: De que forma acontece a aprendizagem dos alunos nestes ambientes? Quais são os instrumentos avaliativos utilizados para acompanhar e mensurar essas aprendizagens? Como o professor se apropria desses novos instrumentos virtuais de acompanhamento e avaliação da aprendizagem? Quais os princípios teóricos que fundamentam essas práticas?

Resenha do livro organizado por Marco Silva e Edméa Santos (São Paulo: Edições Loyola, 2006).

** Professora do Programa de Pós-Graduação em Educação da Pontifícia Universidade Católica do Paraná (PUC-PR). E-mail: dilmeire.vosgerau@pucpr.br 
Para responder a essas novas indagações que estão surgindo, mais uma vez, com muita propriedade, o professor Marco Silva e a professora Edméa Santos, organizadores da obra, imbuídos de um espírito crítico e antecipatório, trazem à tona, em seu livro Avaliação da aprendizagem em educação online, a discussão sobre o processo pedagógico na modalidade de educação a distância e, em especial, a "avaliação". Esta discussão, que é antiga no ensino presencial, mas que ganha uma nova força na educação online, aparece ora como entrave ao processo ensinoaprendizagem que vem sendo construído, ora como agente reflexivo das práticas inseridas nesse processo.

Segundo os autores e organizadores deste livro, com as crescentes iniciativas de oferecimento de cursos online, torna-se emergente um retorno reflexivo às estratégias que vêm sendo utilizadas na avaliação da aprendizagem online. Ressaltam, também, que não podemos levar para o aprendiz a distância as mesmas falhas avaliativas cometidas no processo de ensino-aprendizagem presencial.

Para apresentar as discussões que cingem esta questão, os autores organizam seu livro sob três perspectivas básicas: a teórica, na qual encontramos os fundamentos e conceitos que alicerçam as diversas práticas desenvolvidas por pesquisadores brasileiros e estrangeiros na educação online; a metodológica, em que são apresentados e discutidos exemplos de interfaces e dispositivos utilizados na avaliação; e, finalizando, a perspectiva prática, na qual encontramos os relatos de experiências de pesquisadores que vivenciam a educação online, compartilhando aqui seus anseios e preocupações acerca desta modalidade de ensino-aprendizagem.

É importante ressaltar que, embora haja esta subdivisão, ela não fragmenta os temas abordados, apenas facilita ao leitor a localização rápida dos assuntos específicos de seu interesse e, ao mesmo tempo, a complementação dos temas conforme o avanço da leitura. Exemplo disso são alguns artigos inseridos dentro do capítulo que trata dos fundamentos da educação online, que trazem, também, resultados de pesquisas, ou os ilustram com relatos de experiências. É o caso do artigo intitulado "Teoria da distância transacional e o processo de avaliação da aprendizagem em EAD", no qual são apresentados os elementos essenciais da teoria da distância transacional, o desenvolvimento da autonomia do aprendiz, "o diálogo entre os alunos e a preocupação com a escolha de uma estrutura que possibilite este tipo de vivência”, sendo 
ilustrado pela situação experimentada em uma universidade americana, onde os autores constataram a importância a ser atribuída a um conceito ainda recente no Brasil, o peer mentoring, ou seja, auxílio por pares.

Situação inversa, "prática fundamentada pela teoria", ocorre nos demais capítulos que, mesmo tendo como cerne o detalhamento de modelos e práticas da educação online, trazem uma fundamentação teórica consistente e excelentes referências.

Na primeira parte do livro, que trata dos "fundamentos" da educação online, encontramos os diferentes conceitos de avaliação da aprendizagem e de avaliação do processo pedagógico que tornam viável a construção desta aprendizagem pelo aluno.

No que se refere à avaliação da aprendizagem, no artigo "Pesquisando ambientes de aprendizagem online" a autora sintetiza quatro diferentes cenários de educação a distância: no primeiro, os participante buscam a transmissão de conteúdos (palestras, exposições temáticas etc.); no segundo, são levados pela busca da aprendizagem continuada; no terceiro, a mobilidade dos aprendizes não lhes permite seguir um curso presencial; e, finalmente, no quarto cenário, o ingresso às comunidades de aprendizagem, visando a ampliação de horizontes e perspectivas profissionais ou pessoais.

Esses cenários permitem a compreensão das diferentes propostas de avaliação da aprendizagem descritas nos artigos posteriores, onde, no entanto, os diversos autores que participam da coletânea concordam no valor a ser conferido ao propósito e ao contexto da avaliação, bem como ao seu caráter muito mais formativo do que somativo, visto que, em grande parte das situações de e-learnig, é por meio dela que se reduzirá ou aumentará ainda mais a distância física entre o aprendiz e o formador no processo de ensino-aprendizagem.

Entretanto, não é apenas a escolha do caráter formativo ou somativo da avaliação que determinará o sucesso da utilização do instrumento. Segundo Bliskstein, em seu artigo "Mal-estar da avaliação", os estudos da psicologia cognitiva sobre os modelos mentais do processo de aprendizagem podem contribuir efetivamente para que a avaliação ultrapasse os limites da construção interna. Para tal, discute duas teorias a serem consideradas pelos professores, tanto no ensino presencial quanto a distância: as teorias da cognição distribuída e a da 
cognição situada. Ambas têm em comum que o "aprendiz mostre o que sabe fazer". O autor ainda faz um alerta consciencioso sobre o discurso ambicioso e "carregado de retórica sedutora" baseado nas idéias de autores como Papert e Freire, que "muitas vezes se choca com as dificuldades em transformar tudo isto em prática sustentável na escola”. Alerta, ainda, para o uso excessivo de jargóes associados à educação com o advento da tecnologia, como "colaboração, inteligência coletiva, interação, interatividade" que, "ao invés de facilitar o trabalho dos educadores, está criando mais cobranças impossíveis, contradições teóricas e promessas duvidosas".

Um outro elemento importante, abordado no livro, é a avaliação pedagógica do modelo e do processo de formação oferecido ao aprendiz: em outras palavras, trata-se da avaliação do modelo de ensinoaprendizagem proposto ao aprendiz, situação esta necessária, mas não tão comum no ensino presencial, visto que a sala de aula presencial ainda é um espaço reservado exclusivamente ao professor e ao aluno.

Quando se trata da sala de aula online, as situações pedagógicas transcendem o espaço físico e, de acordo com os artigos "Avaliação no contexto educacional online", situado na primeira parte do livro, e "Dinâmica dos três Cs na avaliação de cursos em e-learning: compreensão, confiança, complementaridade", situado na segunda parte do livro, sugerem que a avaliação dos programas e cursos virtuais implica a participação e o envolvimento de toda a comunidade, formadores, alunos, potenciais formadores e avaliadores externos, partindo assim da premissa de que "é importante avaliar para aprimorar".

$\mathrm{Na}$ segunda parte do livro, os organizadores apresentam textos nos quais pesquisadores nacionais e internacionais discutem a contribuição das interfaces e dos dispositivos utilizados na educação online (diferentes e inovadoras perspectivas teóricas apontadas no primeiro capítulo). Dentre as diversas metodologias apresentadas, destacamos a utilização de portfólios, que permitem o acompanhamento do processo de aprendizagem e conduzem a uma avaliação formativa, bem como a utilização de diferentes recursos, como as ferramentas que contribuem para a construção individual ou conjunta de mapas conceituais, e os blogs, utilizados como instrumentos de expressão pessoal ou de escrita colaborativa.

$\mathrm{Na}$ terceira parte do livro, nos relatos de experiências, encontramos excelentes exemplos das diferentes buscas por um processo avaliativo 
que corrobore com o processo de aprendizagem do aluno. Constatamos aqui, nas experiências relatadas, uma transposição de um modelo quantitativo para um modelo qualitativo de avaliação.

Nesses relatos, entre os diversos temas abordados, destacamos a importância atribuída às estratégias que possibilitem o desenvolvimento da autonomia do aluno, como, por exemplo, o diálogo pedagógico, o trabalho individual com o aluno, visando regular a quantidade e a complexidade dos conteúdos, e os retornos que reforcem ou orientem as atividades dos mesmos. Descobrimos, também, como alguns mitos acerca do ensino virtual podem ser quebrados com práticas adequadas que levam a uma boa educação online. Entre os mitos que são derrubados, destacamos a falsa crença de que o ensino virtual é um ensino de massa e de que, no ensino a distância, os conteúdos são aligeirados, imprimindo então, a esta modalidade de ensino, o valor que ela merece.

Entre os relatos de experiência citados, observamos uma concordância, mesmo que implícita, sobre a importância atribuída à harmonia e à articulação entre todos os envolvidos no processo de planejamento, formatação e execução dos cursos. Possibilitando a todas estas partes formarem um todo, no qual haja coerência entre os objetivos propostos, entre os conteúdos trabalhados, entre as atividades de aprendizagem e entre as atividades avaliativas propostas presencialmente e a distância.

Os artigos apresentados no livro podem servir como referência para novas pesquisas e práticas pedagógicas da educação online. Se utilizados com esta finalidade, salientamos a atualização e a diversidade das referências bibliográficas reunidas pelos autores, nas quais encontramos um vasto material de apoio para futuros trabalhos acadêmicos.

Para planejadores, professores e tutores que atuam ou pretendam atuar em educação a distância, ou, ainda, para aqueles que pretendam utilizar a tecnologia como uma opção a mais para favorecer o processo de ensino-aprendizagem presencial, encontramos, no livro, excelentes exemplos que nos remetem de um processo somativo a um processo formativo e emancipatório de avaliação. 